\title{
Fatigue life evaluation for carbon/epoxy laminate composites under constant and variable block loading
}

\author{
P.N.B. Reis ${ }^{\text {a,* }}$, J.A.M. Ferreira ${ }^{\text {b }}$, J.D.M. Costa ${ }^{\text {b }}$, M.O.W. Richardson ${ }^{c}$ \\ a University of Beira Interior, Electromechanical Engineering Department, Calçada Fonte do Lameiro, Edificío I das Engenharias, 6200-100 Covilhã, Portugal \\ ${ }^{\mathrm{b}}$ CEMUC University of Coimbra, Mechanical Engineering Department, Polo II da Univ. de Coimbra, Rua Luís Reis Santos, Pinhal de Marrocos, 3030-788 Coimbra, Portugal \\ ${ }^{\mathrm{c}}$ RCMI, Department of Mechanical and Design Engineering, University of Portsmouth, Anglesea Road, Portsmouth POI 3DJ, England, United Kingdom
}

\section{A R T I C L E I N F O}

\section{Article history:}

Received 23 June 2008

Received in revised form 17 September

2008

Accepted 23 September 2008

Available online 11 October 2008

\section{Keywords:}

A. Carbon fibres

A. Structural composites

B. Mechanical properties

B. Fatigue

D. Damage mechanics

\begin{abstract}
A B S T R A C T
This paper presents the results of current research on the fatigue life prediction of carbon/epoxy laminate composites involving twelve balanced woven bidirectional layers of carbon fibres and epoxy resin manufactured by a vacuum moulding method. The plates were produced with $3 \mathrm{~mm}$ thickness and 0.66 fibre weight fraction. The dog bone shape specimens were cut from these plates with the load line aligned with one of the fibre directions. The fatigue tests were performed using load control with a frequency of $10 \mathrm{~Hz}$ and at room temperature. The fatigue behaviour was studied for different stress ratios and for variable amplitude block loadings. The damage process was monitored in terms of the stiffness loss. The fatigue life of specimens submitted to block loading tests was modelled using Palmgren-Miner's law and taking in to account the stress ratio effect. The estimated and experimental fatigue lives were compared and good agreement was observed.
\end{abstract}

(c) 2008 Elsevier Ltd. All rights reserved.

\section{Introduction}

Composites are nowadays an alternative, to traditional materials like metals, because of their high stiffness and strength, low weight and adjustable properties. Carbon-fibre-reinforced polymer-matrix composites (CFRPs), for example, have been widely used for aerospace components, sporting goods, structural applications in automobiles, ships, aircraft, etc., as consequence of their beneficial characteristics, such as stability, high specific strength, stiffness and good chemical resistance. Particularity in the automotive and aerospace industries the use of these materials is associated with structural weight reduction and the consequential fuel saving and improved performance [1].

For the industries mentioned above, structural components are usually subjected to complex fatigue load histories [2] characterized by changes in the amplitude, stress ratio $(R)$, frequency and waveform of the cycling stresses. The fatigue behaviour of composites, for example, has been shown to be highly dependent on the stress ratio, $R$, as reported in several literature studies [2-7]. However, in this case, the visco-elastic behaviour of the polymeric matrices has a significant effect on the fatigue life of the composite, in particular for short and randomly distributed fibre composites or when the fibre direction and load direction is different $[8,9]$. Petermann and Schulte [8], for example, observed that for $\pm 45^{\circ}$ an-

\footnotetext{
* Corresponding author. Tel.: +351968 066 552; fax: +351 275329920 .

E-mail address: preis@ubi.pt (P.N.B. Reis).
}

gle-ply laminates of carbon-epoxy tested in tension-tension fatigue at high stress ratios and maximum stresses below the endurance limit, the damage evolution was dominated by creep. According the same authors reported that no creep is to be expected for $R=-1$ because of zero mean stress. In fact the mean load can be considered as static load and consequently the material creeps under its effect. On the other hand, the $0^{\circ}$ angle-plies laminates of carbon-epoxy do not exhibit creep [8].

Mandell and Meier [4] and El-Kadi and Ellyin [5] discussed the effects of the stress ratio on fatigue life of composites materials. They observed that for a given maximum stress in tension- tension loading the fatigue life increases with increasing $R$. In compression-compression loading the increase of $R$ reduces the fatigue life of the composites. On the other hand, Rosenfeld and Huang [6] investigated the effect of the compressive loading on the fatigue behaviour of graphite/epoxy laminates for $R=0$; $-\infty$ and -1 . They concluded that a significant life reduction occurs for both $R=-\infty$ and $R=-1$, being higher for $R=-1$. Rotem and Nelson [7] studied the fatigue behaviour of graphite/epoxy laminates and showed that tension-compression fatigue was more important than tension-tension or compression-compression fatigue. According to El-Kadi and Ellyin [5] the tensile and compressive stresses, in general, do not contribute equally to the damage. The compressive loads produce a significant reduction in fatigue life when compared with results for tension-tension loading [6].

The influence of the mean stress on the fatigue life of a material is presented in a plot, known as the "stress amplitude-mean stress 
diagram", where the stress amplitude $\left(\sigma_{\mathrm{a}}\right)$ is a function of the mean stress $\left(\sigma_{\mathrm{m}}\right)$, for a fixed fatigue life [2]. Abd Allah et al. [2], for example, observed that for a constant cyclic life the permissible initial stress amplitude decreases as the mean stress increases, applying some empirical relationships for predicting mean stress effects on the fatigue life prediction of GFR polyester composites. The results show that the estimated values of $\sigma_{\mathrm{a}}$ using the Peterson's equation [10] have the best agreement with the experimental data. Boller [11] conclude that for $0^{\circ}$ and $\pm 15^{\circ}$ laminates, the cyclic stress amplitude at a constant life decreased with increasing tensile mean stress, but the data did not fit the Goodman equation. Also, Crowther et al. [12] observed that the effect of mean stress on the fatigue strength of a chopped strand mat/woven roving/ chopped strand mat sandwich composite did not fit the Goodman equation. Mallick and Zhou [13] did verify that, for short E-glass fibre reinforced polyamide 6.6, the mean stress effect on the fatigue strength can be described by a modified Gerber equation.

This paper presents the results of a current study concerned with the fatigue behaviour of a balanced woven carbon/epoxy composite. The stress ratio effect on fatigue life is modelled based on experimental $S-N$ curves performed with $R$ values from -1 to +0.4 , at room temperature. The damage process was monitored in terms of the stiffness loss correlated with the failure sites and the mechanisms analysed using microscopy. A series of sequence block tests were performed using, for each sequence block, different stress ratios corresponding to the constant amplitude fatigue tests. For each block loading test the fatigue life is estimated based on the constant stress amplitude $S-N$ curves using PalmgrenMiner's law and compared with experimental results.

\section{Materials processing and testing}

Composite laminate sheets were manufactured using 12 balanced woven bi-directional layers of carbon fibres $\left(196 \mathrm{~g} / \mathrm{m}^{2}\right)$ all of them with the same orientation $0 / 90^{\circ}$, and an epoxy resin matrix. Fibres and resin were hand placed in a mould subjected to low level compression. The mould was then put into a vacuum bag during $8 \mathrm{~h}$ for room temperature curing. Fig. 1 is a schematic view of the manufacturing process. Airtech commercial vacuum

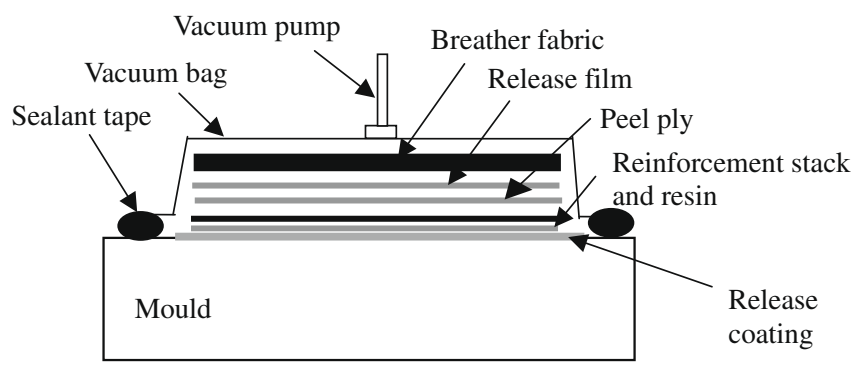

Fig. 1. Schematic view of the manufacturing process.

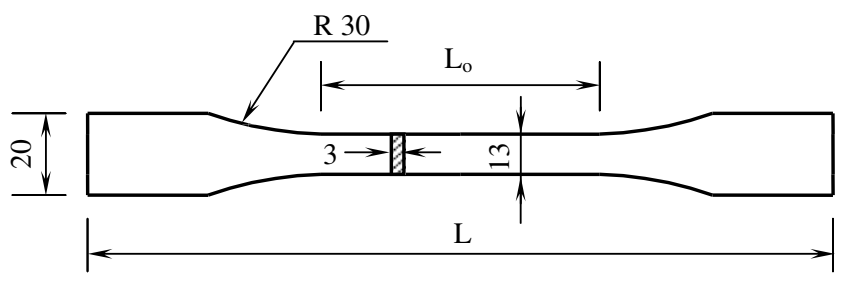

Fig. 2. Geometry and dimensions of the specimens. For static and fatigue tests with $R>0 ; L=160 \mathrm{~mm}$ and $L_{\mathrm{o}}=80 \mathrm{~mm}$. For static and fatigue tests with $R<0$; $L=100 \mathrm{~mm}$ and $L_{\mathrm{o}}=25 \mathrm{~mm}$. consumables, supplied from SP, were used: peel plies Stitch Ply A in Nylon 6-6, release film WL3600 in polypropylene, breather Econoweave $1010 \mathrm{~W}$ produced with polyester fibre and vacuum bag films WL7400 in PA6. The fibre weight fraction was 0.66 and
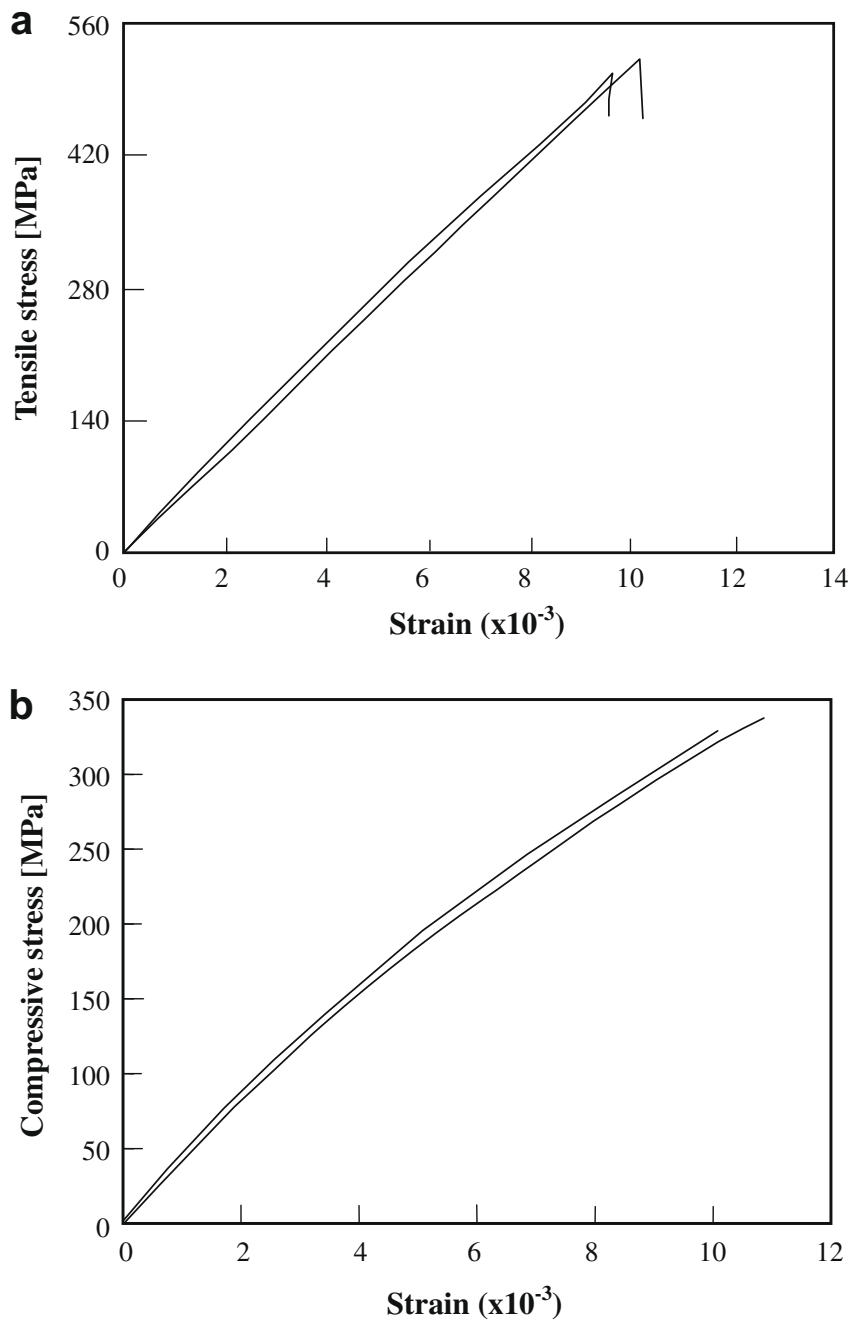

Fig. 3. Typical stress-strain plots: (a) tensile tests and (b) compressive tests.



Fig. 4. Lateral view showing the fibre distribution along of the longitudinal direction of the specimen. 


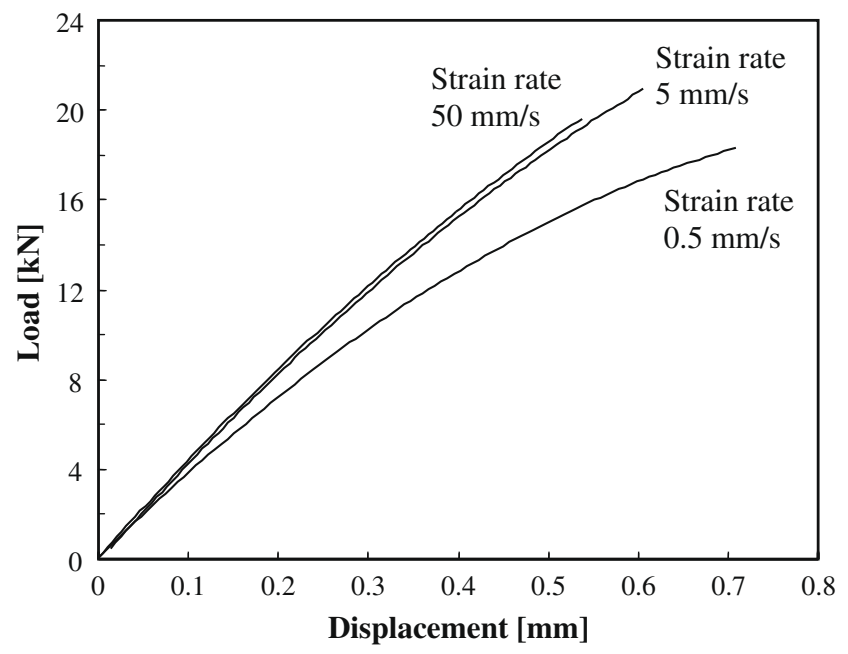

Fig. 5. Typical compressive load-displacement curves showing the effect of the strain rate.

Table 1

Experimental results obtained in the static tests.

\begin{tabular}{|c|c|c|c|c|}
\hline Loading type & $\begin{array}{l}\text { Strain rate } \\
(\mathrm{mm} / \mathrm{s})\end{array}$ & $\begin{array}{l}\sigma_{\text {UTS }} \\
(\mathrm{MPa})\end{array}$ & $\begin{array}{l}\text { Average } \sigma_{\text {UTS }} \\
(\mathrm{MPa})\end{array}$ & $\begin{array}{l}\text { Standard } \\
\text { deviation (MPa) }\end{array}$ \\
\hline Tensile & 5 & $\begin{array}{l}539.2 \\
521.9 \\
568.3 \\
538.6\end{array}$ & 542.0 & 19.3 \\
\hline Compressive & 0.5 & $\begin{array}{l}298.0 \\
330.9 \\
321.1 \\
312.4\end{array}$ & 315.6 & 13.9 \\
\hline Compressive & 5 & $\begin{array}{l}309.4 \\
313.6 \\
330.8 \\
329.0\end{array}$ & 320.7 & 10.8 \\
\hline Compressive & 50 & $\begin{array}{l}322 \\
353.3 \\
342.2 \\
339.5\end{array}$ & 339.3 & 12.9 \\
\hline
\end{tabular}

the average plate thickness was $3 \mathrm{~mm}$. The quality control of the plates was by visual inspections in terms of finish surface and void content.

The specimens used in the tensile, compressive and fatigue tests were cut from these plates and aligned with one of the fibre direction. The geometry and dimensions of the specimens are shown in Fig. 2. The specimens used in compressive tests and fatigue with
$R<0$ were smaller to escape buckling effects. Few compressive tests were carried out with two strain gauges bonded onto both sides of the specimen in order to check the occurrence of buckling.

The static tests were performed in tension using an electromechanical machine (Instron model 4206) according ISO standard [14], with a strain rate of $5 \mathrm{~mm} / \mathrm{s}$. The compressive tests were performed in a servohydraulic machine (Instron model 1341) at a strain rates of $0.05 \mathrm{~mm} / \mathrm{s}, 5 \mathrm{~mm} / \mathrm{s}$ and $50 \mathrm{~mm} / \mathrm{s}$, according to the recommendations of ASTM D 3410/D 3410 M Standard [15]. Four specimens were tested for each condition. The fatigue tests were carried out at room temperature in the same servohydraulic Instron machine using a sinusoidal wave load at constant amplitude and a frequency of $10 \mathrm{~Hz}$. One specimen loaded with the higher displacement was instrumented with thermocouples in order to analyse the increase of temperature during the fatigue tests. No significant variation was observed and, consequently, the other fatigue specimens were not instrumented. Six series of fatigue tests were performed using the stress ratios: $-1,-0.5,-0.25,0.05,0.2$ and 0.4 , respectively.

\section{Results and discussion}

The static properties of the laminated composites were obtained by tensile and compressive tests. Two typical stress-strain curves for both conditions are plotted in Fig. 3. It can be seen that for the tensile tests, Fig. 3a, the curves are practically linear until brittle failure. For compressive tests, Fig. 3b, nonlinear behaviour occurs from the beginning. In fact some studies reveal that the nonlinear elastic behaviour, in both tension and compression ranges, is due to viscoelastic behaviour of the matrix and the nonlinear behaviour of the carbon fibres [16]. The material nonlinearity of carbon fibres are a result of their specific microstructure [17-20]. However, as the tensile tests shows, this material presents linear-elastic behaviour. Therefore the nonlinear elastic behaviour observed in compression tests must be due other explanations. The hypothesis of the general buckling occurrence was discarded by compressive tests with two strain gauges bonded onto both sides of the specimen. Fig. 4 shows that fibres are not perfectly aligned with longitudinal direction in all specimens. While in tension this misalignment tends to decreases with load increasing, in compression tests the opposite phenomenon is expected and consequent microbuckling tends to occur. The increase of the load during the tests promotes an extension of this damage mechanism, which results in a progressive lose of specimen stiffness. Failure mechanisms will be observed later and are in agreement with this explanation.

In order to better understand material nonlinearity in compressive conditions, Fig. 5 shows typical load-displacement curves for strain rates of $0.5 \mathrm{~mm} / \mathrm{s}, 5 \mathrm{~mm} / \mathrm{s}$ and $50 \mathrm{~mm} / \mathrm{s}$, respectively. This effect is more pronounced for lower strain rates $(0.5 \mathrm{~mm} / \mathrm{s})$, where nonlinearity is strongly observed from the beginning. It can also be
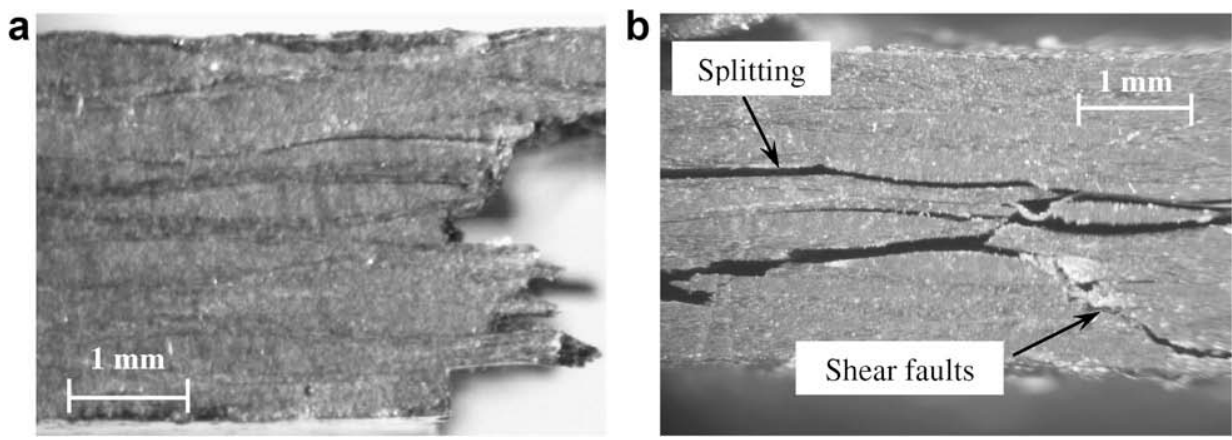

Fig. 6. Lateral view of a static failure for: (a) tensile loadings and (b) compressive loadings. 

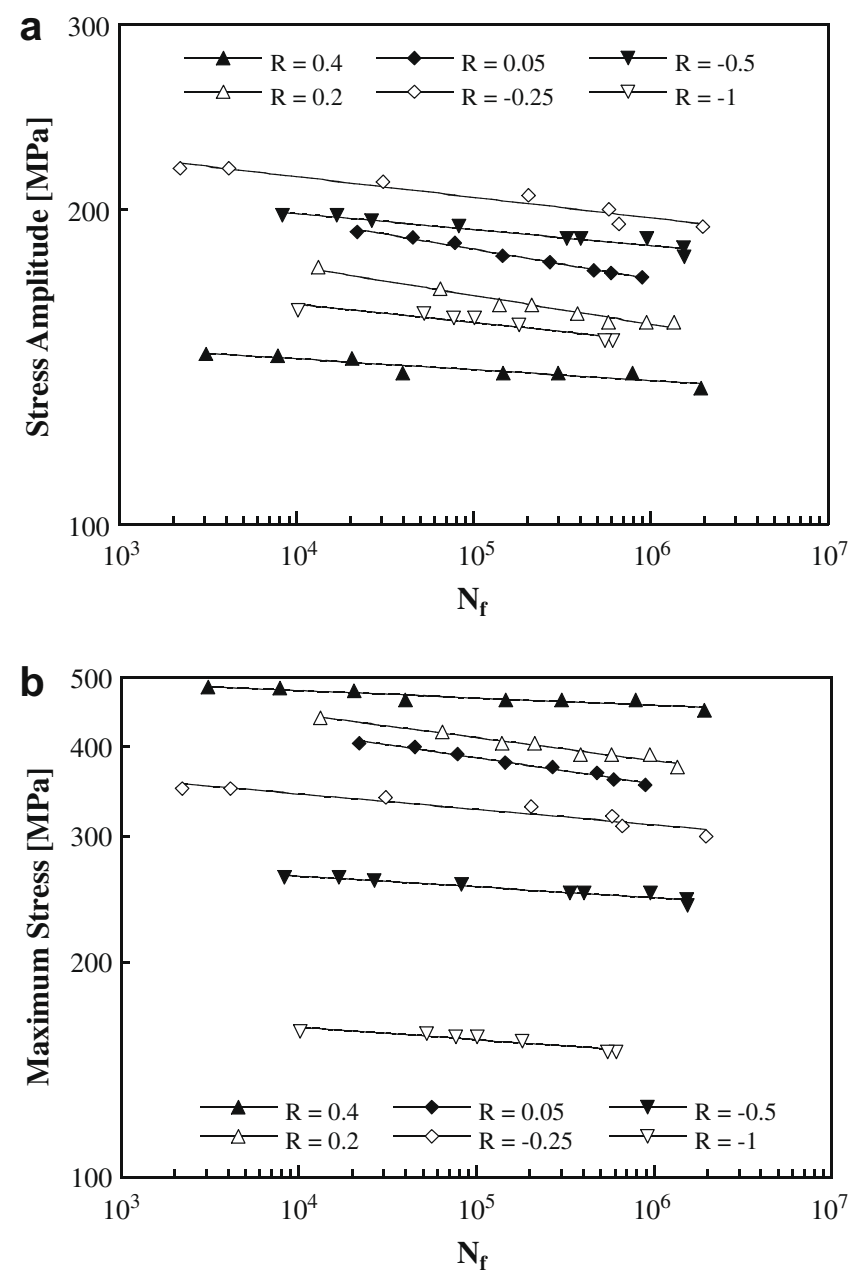

Fig. 7. $S-N$ curves for different mean stresses: (a) stress amplitude versus number of cycles to failure; (b) maximum stress versus number of cycles to failure.

seen that load-displacement curves for strain rates of $5 \mathrm{~mm} / \mathrm{s}$ and $50 \mathrm{~mm} / \mathrm{s}$ are very similar and the nonlinearity is less significant than for $0.5 \mathrm{~mm} / \mathrm{s}$.

Table 1 presents all the experimental results obtained from the static tests plus average values and the respective standard devia- tions. It is possible to observe that ultimate strength for a strain rate of $5 \mathrm{~mm} / \mathrm{s}$, defined as the stress at peak load, for the tensile tests, is around $69 \%$ higher than for the compressive tests. On the other hand, the difference between the compressive strengths observed for strain rates of $0.5 \mathrm{~mm} / \mathrm{s}$ and $50 \mathrm{~mm} / \mathrm{s}$ is about $7 \%$. The compressive strength increases with the increasing in strain rate. The lower compressive strength of the composite was expected and the differences observed from the tensile values are very close to the literature [21,22]. According to Berbinau et al. [21] and Goutianos et al. [22] the compressive failure of unidirectional fibrous composites is typically $60-70 \%$ of their tensile strength and it is a consequence of different failure mechanisms.

Fig. 6 shows the main failure mechanisms observed for tensile and compressive loadings. Agreeing with the bibliography $[23,24]$, for the tensile specimens tested (Fig. 6a), the fracture of the fibres in the longitudinal direction is accompanied with some longitudinal delaminations between layers. According to Mittelman and Roman [24] the final rupture is controlled by the strain. On the other hand, for compressive loadings (Fig. 6b), it is possible to observe a region where the fibres broke, forming a line with an angle around $45^{\circ}$ with the loading direction, and with some cracks propagating parallel to the load direction. In agreement with the studies of Nakanishi et al. [25] this fracture morphology is very similar with the mode that they classify as shear mode, with not many vertical cracks but exhibiting fracture surfaces which are at an angle of about $45^{\circ}$ to the loading direction. However, in another region, an axial splitting fault and also a combination of two failure modes (shear and splitting) was observed, as reported by Lankford [26]. From the literature [21,27] it can be inferred that the initial mechanisms for compressive failure of composite materials are usually microbuckling and kinking of the fibres aligned with the load direction.

The fatigue tests were carried out at constant stress amplitude for the six stress ratio $R$ ( $R=$ minimum stress/maximum stress), and the results are plotted in Fig. 7a and b) in terms of stress amplitude versus number of cycles to failure and maximum stress versus number of cycles to failure, respectively. The present results confirm the trend reported in literature that the fatigue strength in terms of maximum stress increases with $R$ values, even for negative values [4-7]. The effect of mean stress observed in this case is very significant. The negative stress ratio tests present a drastic decrease of fatigue strength as a consequence of the lower compressive strength of the laminate composites and different main failure mechanisms. When fatigue strength is quantified in terms
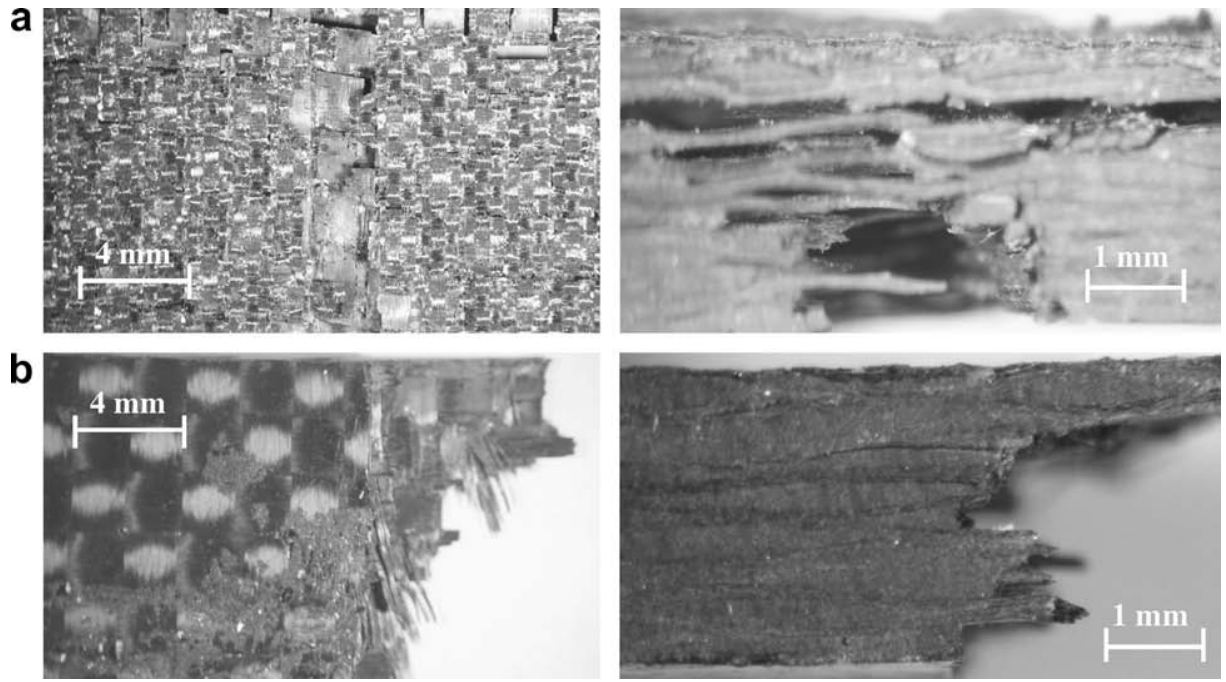

Fig. 8. Examples of failures following fatigue testing: (a) positive stress ratio $(R=0.05)$ and (b) negative stress ratio $(R=-0.5)$. 
of the stress amplitude it decreases with the increasing of stress ratio for positive values. However for negative $R$ values a decrease of fatigue strength was also observed as a consequence of the much lower ultimate compressive strength associated with the failure mechanisms. According literature $[5,6]$ the tensile and compressive parts of the stress cycle do not contribute equally to the composite's damage. The compressive loads produce higher levels of damage and consequently reduce significantly the fatigue life [6].

Fig. 8 presents optical photos showing the upper and lateral views of the main significant sites and failure mechanisms observed during the tests. The failure mode observed for tension-tension fatigue tests depends on the magnitude of the applied stress.
For relatively high stress levels, close to the ultimate tensile strength, short delaminations were observed before final fibre breakage, while for lower stress levels long delaminations occurred over an extended period of time. These failure mechanisms are according the studies developed by El-Kadi and Ellyin [5]. On the other hand, for tension-compression fatigue tests, the failure starts with the breakage of the fibres, as a consequence of microbuckling and kinking of the fibres aligned with the load direction, followed by cracking parallel to the load direction.

The stiffness modulus was measured during fatigue tests. The peak load and displacement were monitored and used to calculate the stiffness modulus $(E)$, defined by the ratio axial stress/axial
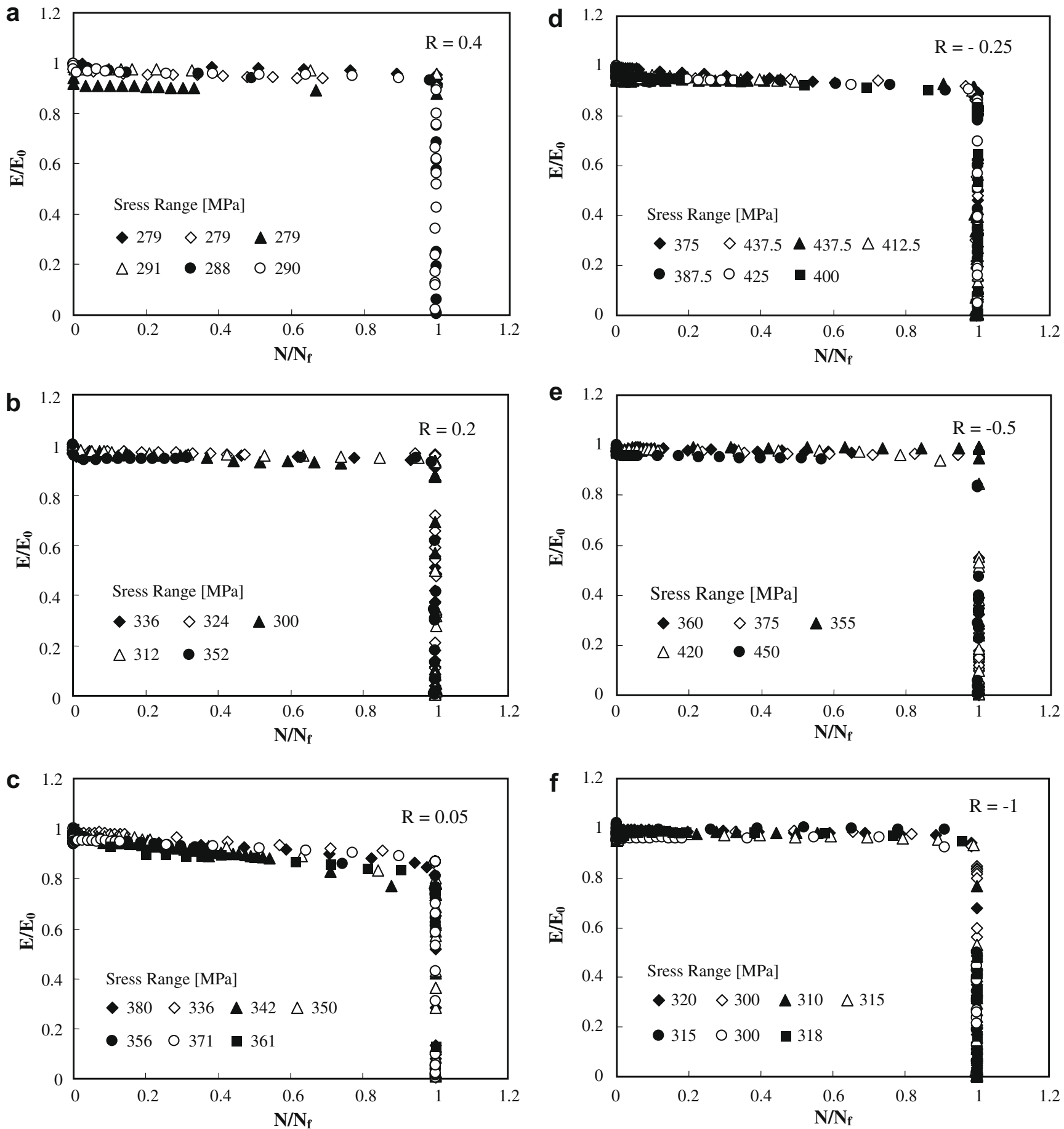

Fig. 9. $E / E_{0}$ versus $N / N_{\mathrm{f}}$ for tests with different $R$ values. 
strain. Fig. 9 plots $E / E_{0}$ versus $\mathrm{N} / \mathrm{N}_{\mathrm{f}}$, for different tests with the six $R$ values, where $E_{0}$ is the initial value of $E, \mathrm{~N}$ the current number of cycles and $N_{\mathrm{f}}$ is the number of cycles to failure. The results show in all cases a slight drop in stiffness modulus during the first fatigue cycles, followed by a region with a stable decrease of $E / E_{0}$ until the final failure. The present behaviour confirms the trend reported in literature [28-31]. The slope and shape of the plot in the stable region appears to be not dependent on both the $R$ value and the stress amplitude. The results for different loads and $R$ values show lower differences than the scatter of results usually observed. The effect of the mean stress on the fatigue strength in terms of the stress amplitude is presented in Fig. 10a for fixed cyclic lives of $10^{5}$ and $10^{6}$ cycles. It is at once evident that, in terms of the stress amplitude, the fatigue strength losses for low mean stresses (negative $R$ values). This plot also shows that the linear relationship of the Goodman Law between stress amplitude and mean stress does not fit the experimental results for low mean stresses. A quadratic equation, including a linear term to account the loss of fatigue strength for negative stress ratios, is in better agreement with experimental results plotted in Fig. 10b) as the stress amplitude against the dimensionless parameter $\sigma_{\mathrm{m}} / \sigma_{\mathrm{UTS}}$. The fitted equation is:

$\sigma_{a}=\sigma_{f}+A\left(\frac{\sigma_{m}}{\sigma_{U T S}}\right)-B\left(\frac{\sigma_{m}}{\sigma_{U T S}}\right)^{2}$

where $\sigma_{\mathrm{a}}$ is the stress amplitude, $\sigma_{\mathrm{f}}$ is the stress amplitude strength for reverse loadings, $\sigma_{\mathrm{m}}$ is the mean stress, $\sigma_{\text {UTS }}$ is the ultimate ten-
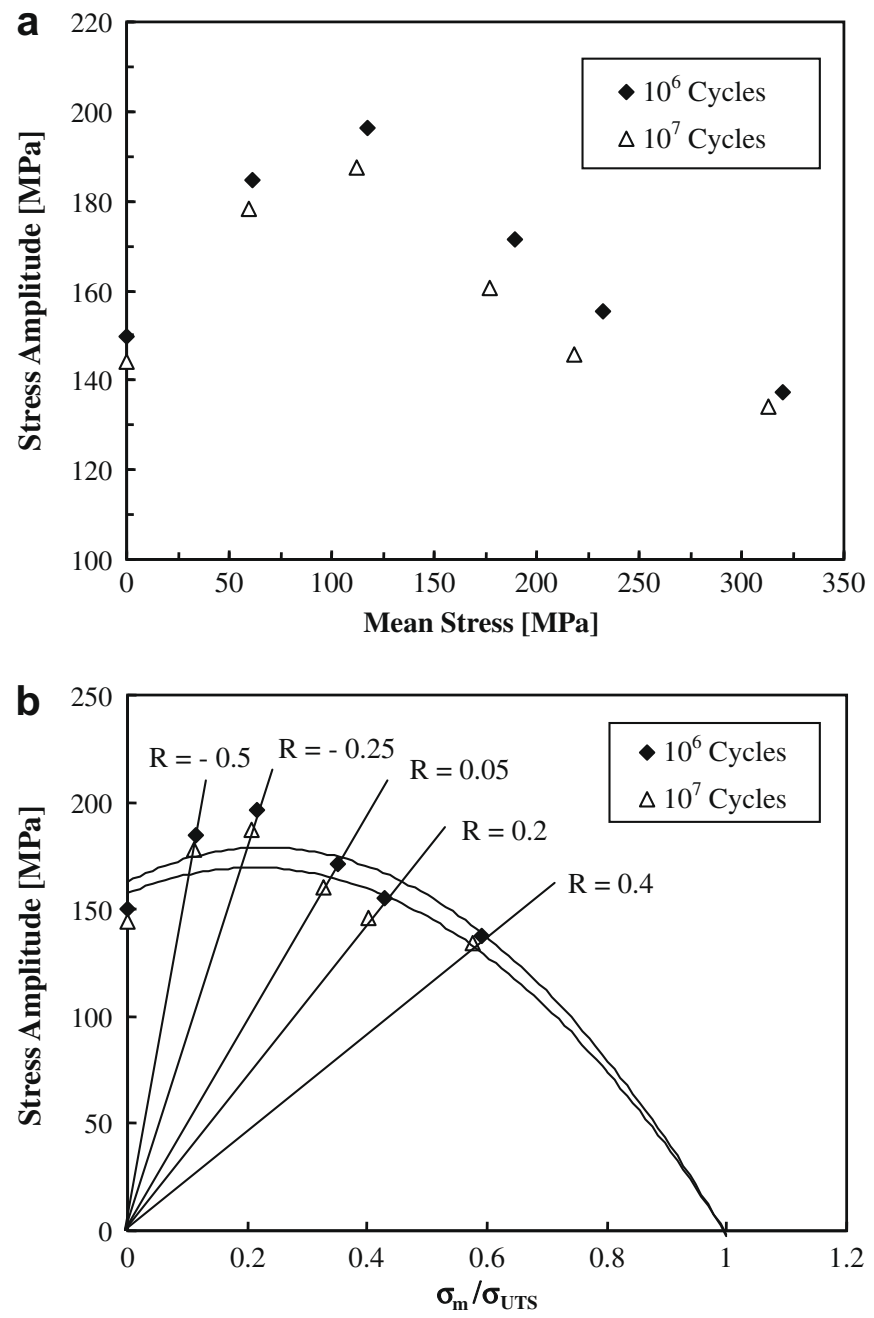

Fig. 10. Fatigue results: (a) stress amplitude-mean stress diagram; (b) correlation in terms of the stress amplitude versus mean stress.

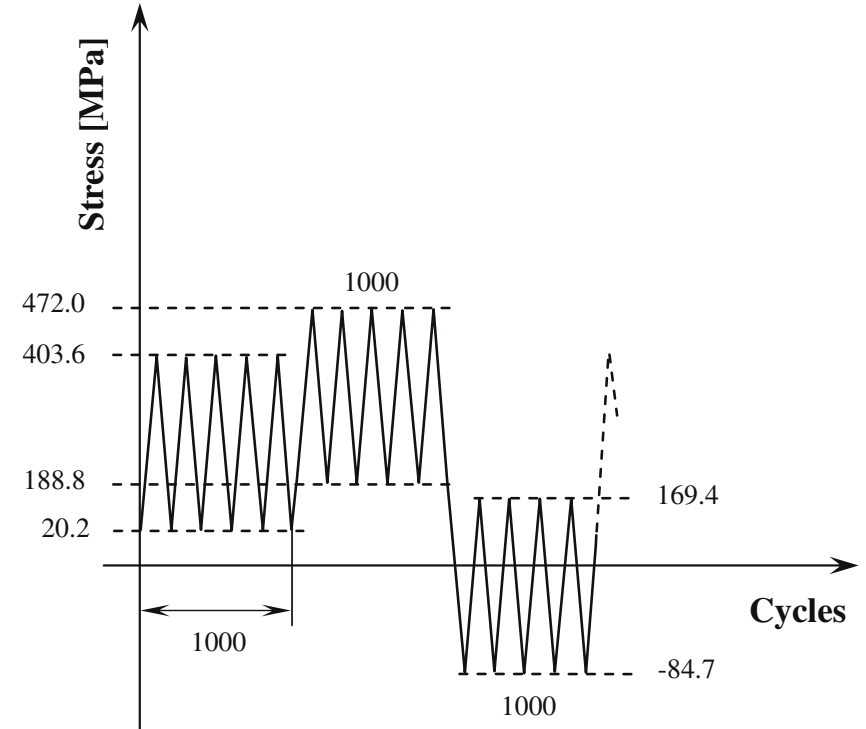

Fig. 11. Typical example of block loading sequence.

sile strength, $\mathrm{A}$ and $\mathrm{B}$ are constants dependent of the material and fatigue life. The fitted values are: $\sigma_{\mathrm{f}}=108.35 \mathrm{MPa}, A=358.36 \mathrm{MPa}$, $B=-468.08 \mathrm{MPa}$ for $10^{5}$ and $\sigma_{\mathrm{f}}=102.07 \mathrm{MPa}, A=309.95 \mathrm{MPa}$ and $B=-412.09 \mathrm{MPa}$ for $10^{6}$ cycles.

A series of sequence block tests were performed, using for each, sequence blocks with different stress ratios corresponding to the constant amplitude fatigue tests. Fig. 11 shows schematically an example of block loading sequence. Table 2 presents the sequence parameters and fatigue life for each test. According Sonsino [32] for valid variable amplitude loading (VAL) test, the sequence must be repeated at least 5-10 times in order to achieve a service-like load mixing. In the present work the sequence was repeated at least eight times.

For each variable stress amplitude test, the fatigue life is estimated using constant stress amplitude $S-N$ curves using linear damage accumulation Palmgren-Miner's Law and then compared to the experimental values. The comparison of estimated and experimental results is presented in Fig. 12, where are also plotted two curves corresponding to a tolerance range three times higher or lower then the estimated against the experimental values. Estimated points are within the tolerance range and the average ratio between predictions and experimental lives are close to unit. Therefore, it can be concluded that the method is accurate enough for predictive fatigue design.

The tests were carried out under variable block loading. However, in practice the loading has a random character. The comparison of results obtained for other materials under same spectrum shape, but once applied with blocked loads and once with randomly distributed loads shows a lower fatigue life for random loading (see Ref. [32]), if the sequence length of the spectrum is too long and the repetition is too low. This aspect should be considered for the tested materials in future investigations.

\section{Conclusions}

- The tensile ultimate strength obtained for woven balanced bidirectional laminated carbon/epoxy composites is significantly higher (about 69\%) than the compressive ultimate strength. Under tensile loading the composites exhibit brittle behaviour, while in compressive tests some nonlinear behaviour was observed, which may be consequence of progressive fibre buckling. 
Table 2

Sequence parameters and fatigue lives for the block tests.

\begin{tabular}{|c|c|c|c|c|c|c|c|c|c|}
\hline$\sigma_{\max 1}(\mathrm{MPa})$ & $\sigma_{\min 1}(\mathrm{MPa})$ & $n_{1}$ (cycles) & $\sigma_{\max 2}(\mathrm{MPa})$ & $\sigma_{\min 2}(\mathrm{MPa})$ & $n_{2}$ (cycles) & $\sigma_{\max 3}(\mathrm{MPa})$ & $\sigma_{\min 3}(\mathrm{MPa})$ & $n_{3}$ (cycles) & $N_{\mathrm{f}}$ (cycles) \\
\hline 421.7 & 21.1 & 1000 & 412.2 & 82.4 & 1000 & 468.6 & 187.4 & 1000 & 25,900 \\
\hline 403.6 & 20.2 & 1000 & 472.0 & 188.8 & 1000 & 169.4 & -84.7 & 1000 & 56,067 \\
\hline 403.6 & 20.2 & 1000 & 412.2 & 82.4 & 1000 & 468.6 & 187.4 & 1000 & 34,358 \\
\hline 403.6 & 20.2 & 1000 & 169.4 & -84.7 & 1000 & - & - & - & 89,451 \\
\hline 403.6 & 20.2 & 1000 & 169.4 & -84.7 & 1000 & - & - & - & 179,400 \\
\hline 403.6 & 20.2 & 1000 & 412.2 & 82.4 & 1000 & 457.6 & 183.0 & 1000 & 354,396 \\
\hline 412.2 & 82.4 & 1000 & 457.6 & 183.0 & 1000 & 163.0 & -81.5 & 1000 & 113,449 \\
\hline 412.2 & 82.4 & 1000 & 457.6 & 183.0 & 1000 & 163.0 & -81.5 & 1000 & 140,272 \\
\hline 348.8 & 17.4 & 1000 & 382.6 & 76.5 & 1000 & 163.0 & -81.5 & 1000 & 724,373 \\
\hline 348.8 & 17.4 & 1000 & 163.0 & -81.5 & 1000 & - & - & - & 818,355 \\
\hline 403.6 & 20.2 & 1000 & 468.6 & 187.4 & 1000 & 169.4 & -84.7 & 1000 & 200,147 \\
\hline 403.6 & 20.2 & 1000 & 382.6 & 76.5 & 1000 & 169.4 & -84.7 & 1000 & 301,064 \\
\hline
\end{tabular}

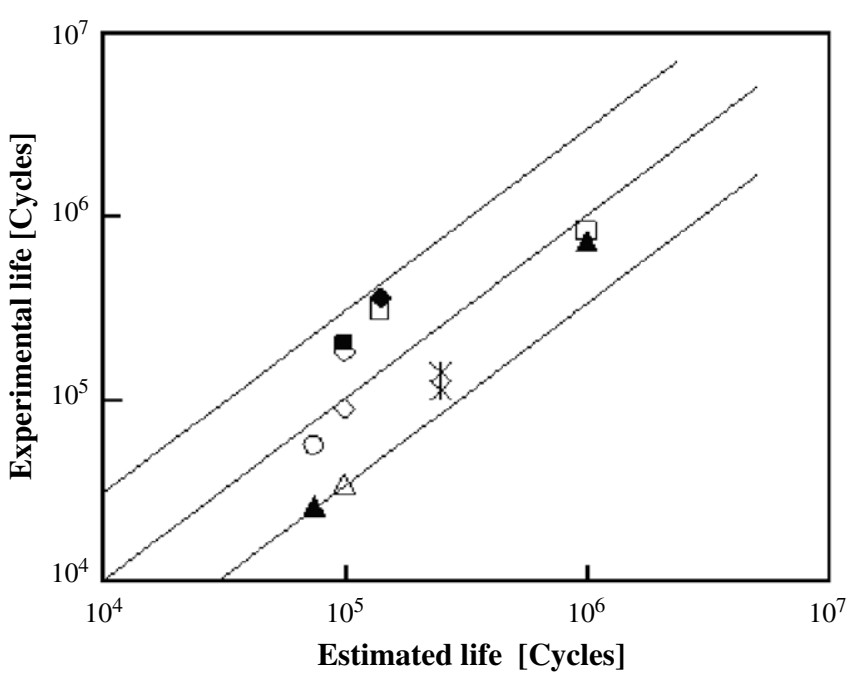

Fig. 12. Experimental and estimated block fatigue test results.

- Fatigue behaviour studied for stress ratios ranging from -0.5 to 0.4 shows a strong dependency on dependent of stress ratio. For negative stress ratios a drastic decay of the fatigue strength was observed as a consequence of much lower ultimate compressive strengths and fibre buckling. A quadratic equation, including a linear term to account the loss of fatigue strength for negative stress ratios, fitted as a function of the stress rate shows good agreement with experimental results.

- The fatigue lives resulting from block loading tests and estimated lives based on Palmgren-Miner's Law were found to be in a good agreement.

\section{Acknowledgement}

The authors would thank by NATO Research \& Technology Organization for sponsoring the work reported (Project Avt-PRT-01).

\section{References}

[1] Shimokawa T, Hamaguchi Y. Distribution of fatigue life and fatigue strength in notched specimens of a carbon eight-harness-satin laminate. J Compos Mater 1983;17:64-76.

[2] Abd Allah MH, Abdin EM, Selmy AI, Khasshaba UA. Effect of mean stress on fatigue behaviour of GFRP pultruded rod composites. Compos: Part A 1997;28A:87-91.

[3] Kawai M. A phenomenological model for off-axis fatigue behavior of unidirectional polymer matrix composites under different stress ratios. Compos: Part A 2004;35:955-63.

[4] Mandell JF, Meier Urs. Effect of stress ratio, frequency and loading time on the tensile fatigue of glass-reinforced epoxy. ASTM STP 1982;813:55-77.

[5] El-Kadi H, Ellyin F. Effect of stress ratio on the fatigue of unidirectional glass fibre/epoxy composite laminates. Composites 1994;25(10):917-24.
[6] Rosenfeld MS, Huang SL. Fatigue characteristics of graphite/epoxy laminates under compressive loading. J Aircraft 1978;15:264-8.

[7] Rotem A, Nelson HG. Failure of a laminated composite under tensioncompression fatigue loading. Compos Sci Technol 1989;36:45-62.

[8] Petermann J, Schulte K. The effects of creep and fatigue stress ratio on the longterm behaviour of angle-ply CFRP. Compos Struct 2002;57:205-10.

[9] Epaarachchi JA, Clausen PD. An empirical model for fatigue behavior prediction of glass fibre-reinforced plastic composites for various stress ratios and test frequencies. Compos: Part A 2003;34:313-26.

[10] Weibull W. Fatigue testing and analysis of results. Pergamon Press; 1961.

[11] Boller $\mathrm{KH}$. Effect of tensile mean stress on the fatigue properties of plastic laminates reinforced with unwoven glass fibers. US Air Force Materials Laboratory, Report N ML-TDR-64-86, 1964

[12] Crowther MF, Wyatt RC, Phillips MG. Creep-fatigue interaction in glass fibre/ polyester composites. Compos Sci Technol 1989;36:191-210.

[13] Mallick PK, Zhou Y. Effect of mean stress on the stress-controlled fatigue of a short E-glass fiber reinforced polyamide-6.6. Int J Fatigue 2004;26:941-6.

[14] ISO/FDIS 527-4. Plastics - determination of tensile properties - part 4: test conditions for isotropic and orthotropic fibre-reinforced plastic composites. ISO International Standard; 1996.

[15] American Society for Testing and Materials. Standard test method for compressive properties of polymer matrix composite materials with unsupported gage section by shear loading. Annual book of ASTM standards, vol. 15.03, 1999 [D 3410/D 3410M-95].

[16] Yokozeki T, Ogasawara T, Ishikawa T. Effects of the fiber nonlinear properties on the compressive strength prediction of unidirectional carbon-fiber composites. Compos Sci Technol 2005;65:2140-7.

[17] van Dreumel WHM, Kamp HM. Non Hookean behaviour in the fibre direction of carbon-fibre composites and the influence of fibre waviness on the tensile properties. J Compos Mater 1977;11:461-9.

[18] Ishikawa T, Matsusima M, Hayashi Y. Hardening non-linear behaviour in longitudinal tension of unidirectional carbon composites. J Mater Sci 1985;20:4075-83.

[19] Yokozeki T, Ogasawara T, Ishikawa T. Nonlinear behavior and compressive strength of unidirectional and multidirectional carbon fiber composite laminates. Compos: Part A 2006;37:2069-79.

[20] Kyriakides S, Arseculeratne R, Perry EJ, Liechti KM. On the compressive failure of fiber reinforced composites. Int J Solids Struct 1995;32:689-738.

[21] Berbinau P, Soutis C, Guz IA. Compressive failure of $0^{\circ}$ unidirectional carbonfibre-reinforced plastic (CFRP) laminates by fibre microbuckling. Compos Sci Technol 1999;59:1451-5.

[22] Goutianos S, Galiotis C, Peijs T. Compressive failure mechanisms in multi-fibre microcomposites. Compos: Part A 2004;35:461-75.

[23] Zweben C. Tensile failure analysis of fibrous composites. AIAA J 1968;6:2325-6.

[24] Mittelman A, Roman I. Tensile properties of real unidirectional kevlar/epoxy composites. Composites 1990;21(1):63-9.

[25] Nakanishi Y, Hana K, Hamada H. Fractography of fracture in CFRP under compressive load. Compos Sci Technol 1997;57:1139-47.

[26] Lankford J. Shear versus dilatational damage mechanisms in the compressive failure of fibre-reinforced composites. Compos: Part A 1997;28:215-22.

[27] Lee SH, Yerramalli CS, Waas AM. Compressive splitting response of glass-fiber reinforced unidirectional composites. Compos Sci Technol 2000;60:2957-66.

[28] Salekeen S, Jones DL. Fatigue response of thick section fiberglass/epoxy composites. Compos Struct 2007;79:119-24.

[29] Ferreira JAM, Costa JDM, Reis PNB, Richardson MOW. Analysis of fatigue and damage in glass-fibre-reinforced polypropylene composite materials. Compos Sci Technol 1999;59:1461-7.

[30] Ferreira JAM, Costa JDM, Reis PNB. Static and fatigue behaviour of glass-fibrereinforced polypropylene composites. Theor Appl Fract Mech 1999;31:67-74.

[31] Reis PNB, Ferreira JAM, Antunes FV, Costa JDM. Flexural behaviour of hybrid laminated composites. Compos: Part A 2007;38:1612-20.

[32] Sonsino CM. Fatigue testing under variable amplitude loading. Int J Fatigue 2007;29:1080-9. 